\title{
Why do alpine plants grow where they do?
}

\author{
Susanna Venn
}

This project led by Dr Susanna Venn was not written up as a full report but is included here as an abstract.

\section{Abstract}

In an alpine landscape, sharp gradients in climate factors such as wind, snow accumulation and temperature, and physical factors such as topography, aspect and soil, all interact to create environmental gradients, along which various groups of plants will find suitable for habitat. These environmental factors act as filters to exclude species with unviable physiological limitations from entering and persisting in different communities. It is these environmental filters and sharp gradients in habitat suitability that produce the distinct patterns in plant communities that we see in the alpine landscape. However, species per se do not respond to environmental factors; rather, it is how they function within their community and interact with other species that determines where they grow and how successful they are. And thus, an understanding of plant functional traits becomes important for understanding how species and communities will respond to differences and changes in these environmental factors/filters.

Plant functional traits, or morphological traits such as height, size, growth form, specific leaf area and leaf chlorophyll content, are the physical characteristics of species that reveal how plants capture and conserve resources, and how they interact with their environment and each other. As such, plant functional traits underpin the functioning of ecosystems (McGill et al. 2006). For example, plant height can indicate a species' overall competitive ability (tall plants can overtop neighbouring plants as they compete for light and space) as well as being an indirect measurement for biomass, lateral spread, rooting depth and leaf size. Specific leaf area (SLA), the ratio of the area of a fresh leaf to its dry mass, can indicate how plants allocate resources; 
low SLA values correspond to relatively long-lived leaves with high investments in defences or other structural adaptations to cope with harsh conditions (Leishman and Westoby 1992). Ecologists can use trait-based approaches to predict where certain types of species might be found across landscapes or environmental gradients, or even how various plant communities might respond to climate change via changes to the local driving environmental factors (Venn et al. 2011).

In this project, we hiked to and surveyed several contrasting plant communities near Charlotte Pass. We compared them floristically and functionally by measuring various plant functional traits. In this way, we were able to determine which ecological processes (as inferred from their traits) might be driving each of the communities we sampled, and gave us an idea of how these communities might respond to future changes in environmental drivers.

\section{References}

Leishman M, Westoby M (1992) Classifying plants into groups on the basis of associations of individual traits: Evidence from Australian semi-arid woodlands. Journal of Ecology 80(3): 417-24. doi. org/10.2307/2260687

McGill BJ, Enquist, BJ, Weiher E, Westoby M (2006) Rebuilding community ecology from functional traits. Trends in Ecology and Evolution 21: 178-85. doi.org/10.1016/j.tree.2006.02.002

Venn SE, Green K, Pickering, CM, Morgan, JW (2011) Using plant functional traits to explain community composition across a strong environmental filter in Australian alpine snowpatches. Plant Ecology 212: 1491. doi.org/10.1007/s11258-011-9923-1 
This text is taken from Researching functional ecology in Kosciuszko National Park, edited by Hannah Zurcher, Chia Ming-Dao, Michael Whitehead and Adrienne Nicotra, published 2017 by ANU eView, The Australian National University, Canberra, Australia. dx.doi.org/10.22459/RFEKNP.11.2017.06 